\title{
Frequency and characteristics of infusion reactions during biosimilar infliximab treatment in inflammatory bowel diseases: results from Central European nationwide cohort
}

Anita Bálint, Mariann Rutka, Zsuzsanna Végh, Zsuzsanna Kürti, Krisztina B. Gecse, János Banai, László Bene, Beáta Gasztonyi, Tünde Kristóf, László Lakatos, Pál Miheller, Károly Palatka, Árpád Patai, Ágnes Salamon, Tamás Szamosi, Zoltán Szepes, Gábor Tamás Tóth, Áron Vincze, Renáta Bor, Ágnes Milassin, Anna Fábián, Ferenc Nagy, Martin Kolar, Martin Bortlik, Dana Duricova, Veronika Hruba, Martin Lukas, Katarina Mitrova, Karin Malickova, Milan Lukas, Péter L. Lakatos, Tamás Molnár \& Klaudia Farkas

To cite this article: Anita Bálint, Mariann Rutka, Zsuzsanna Végh, Zsuzsanna Kürti, Krisztina B. Gecse, János Banai, László Bene, Beáta Gasztonyi, Tünde Kristóf, László Lakatos, Pál Miheller, Károly Palatka, Árpád Patai, Ágnes Salamon, Tamás Szamosi, Zoltán Szepes, Gábor Tamás Tóth, Áron Vincze, Renáta Bor, Ágnes Milassin, Anna Fábián, Ferenc Nagy, Martin Kolar, Martin Bortlik, Dana Duricova, Veronika Hruba, Martin Lukas, Katarina Mitrova, Karin Malickova, Milan Lukas, Péter L. Lakatos, Tamás Molnár \& Klaudia Farkas (2017) Frequency and characteristics of infusion reactions during biosimilar infliximab treatment in inflammatory bowel diseases: results from Central European nationwide cohort, Expert Opinion on Drug Safety, 16:8, 885-890, DOI: 10.1080/14740338.2017.1323330

To link to this article: http://dx.doi.org/10.1080/14740338.2017.1323330

Pी?

Accepted author version posted online: 15 May 2017. Published online: 26 May 2017.

III Article views: 216

Submit your article to this journal

View Crossmark data $\nearrow$

Citing articles: 2 View citing articles 지 


\section{Frequency and characteristics of infusion reactions during biosimilar infliximab treatment in inflammatory bowel diseases: results from Central European nationwide cohort}

Anita Bálint ${ }^{a}$, Mariann Rutka ${ }^{a}$, Zsuzsanna Végh ${ }^{b}$, Zsuzsanna Kürtib ${ }^{b}$ Krisztina B. Gecse ${ }^{b}$, János Banaic, László Bene ${ }^{d}$, Beáta Gasztonyie, Tünde Kristóff, László Lakatos ${ }^{\mathrm{g}}$, Pál Mihellerh', Károly Palatka', Árpád Patai', Ágnes Salamonk, Tamás Szamosic, Zoltán Szepes ${ }^{a}$, Gábor Tamás Tóth', Áron Vinczem ${ }^{m}$, Renáta Bor ${ }^{a}$, Ágnes Milassina ${ }^{a}$, Anna Fábián (1) ${ }^{a}$, Ferenc Nagya ${ }^{a}$, Martin Kolar ${ }^{n, o}$, Martin Bortlik ${ }^{n, p}$, Dana Duricova ${ }^{n, q}$, Veronika Hruba $^{n}$, Martin Lukas ${ }^{n}$, Katarina Mitrova ${ }^{n, r}$, Karin Malickovas, Milan Lukas ${ }^{\mathrm{n}, \mathrm{s}}$, Péter L. Lakatos ${ }^{\mathrm{b}}$, Tamás Molnár ${ }^{\mathrm{a}}$ and Klaudia Farkas ${ }^{\mathrm{a}}$

${ }^{a}$ First Department of Medicine, University of Szeged, Szeged, Hungary; ${ }^{b}$ First Department of Internal Medicine, Semmelweis University, Budapest, Hungary; 'Military Hospital - State Health Centre, Budapest, Hungary; ${ }^{\mathrm{d}} 1$ st Department of Medicine, Peterfy Hospital, Budapest, Hungary; ${ }^{2} 2 \mathrm{nd}$ Department of Medicine, Zala County Hospital, Zalaegerszeg, Hungary; f2nd Department of Medicine, B-A-Z County and University Teaching Hospital, Miskolc, Hungary; ${ }^{9}$ Department of Internal Medicine, Csolnoky Ferenc Regional Hospital, Veszprém, Hungary; ${ }^{\mathrm{h} S e c o n d}$ Department of Internal Medicine, Semmelweis University, Budapest, Hungary; institute of Medicine, Department of Gastroenterology, University of Debrecen, Clinical Center, Debrecen, Hungary; 'Department of Medicine and Gastroenterology, Markusovszky Hospital, Szombathely, Hungary; ${ }^{k}$ Department of Gastroenterology, Tolna County Teaching Hospital, Szekszárd, Hungary; 'Department of Gastroenterology, Janos Hospital, Budapest, Hungary; ${ }^{\mathrm{m}} 1$ st Department of Medicine, University of Pécs, Pécs, Hungary; ${ }^{n}$ IBD Clinical and Research Centre, Iscarea.s., Prague, Czech Republic; ${ }^{\circ} 1 \mathrm{st}$ Medical

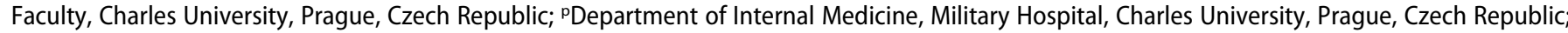
qInstitute of Pharmacology, 1st Medical Faculty, Charles University, Prague, Czech Republic; 'Department of Paediatrics, Faculty Hospital Motol, 2nd Medical Faculty, Charles University, Prague, Czech Republic; Institute of Medical Biochemistry and Laboratory Diagnostics, 1st Medical Faculty and General Teaching Hospital, Charles University, Prague, Czech Republic

\section{ABSTRACT}

Background: Safety data of the 'real life' use of an infliximab biosimilar, CT-P13 in inflammatory bowel disease (IBD) are still lacking. Our aim was to assess the frequency and characteristics of infusion reactions during CT-P13 therapy in 13 Hungarian and 1 Czech IBD centres.

Methods: Clinical and safety data was registered at fixed appointments. Trough levels and anti-drug antibody (ADA) concentration were measured by ELISA. Association between demographic, clinical, laboratory parameters and infusion reaction rates were evaluated statistically.

Results: Three hundred and eighty-four IBD patients were included. Twenty-eight Hungarian IBD patients $(9.6 \%)$ developed infusion reaction during the treatment, $64.3 \%$ of them was previously exposed to anti TNF therapy. No infusion reaction occurred in the Czech population. CT-P13 therapy had to be stopped in 17 patients who developed infusion reaction and was switched to adalimumab in 12 patients. However in $39.3 \%$ of patients developing infusion reaction CT-P13 therapy was continued with the use of premedication. Cumulative ADA positivity rates were $8.7 \%, 19.3 \%$, and $28.0 \%$ at weeks 0 , 14 , and 30. Previous anti-TNF-alpha exposure (30\% vs. $3.1 \%, p<0.001$, OR $6.3(2.7-14.6)$ ) and ADA positivity $(32.6 \%$ vs. $4.1 \%, p<0.001$, OR $19(5-73))$ during the induction therapy were predictive factors for infusion reactions.

Conclusions: Patients with previous exposure to anti-TNF-alpha and ADA positivity during the induction therapy were more likely to develop infusion reactions.
ARTICLE HISTORY

Received 29 April 2016 Accepted 23 April 2017

KEYWORDS

Crohn's disease; ulcerative colitis; infliximab; biosimilar; CT-P13; infusion reaction

\section{Introduction}

After some case series, a large, prospective Hungarian multicenter study has confirmed the efficacy of CT-P13, the first infliximab biosimilar, in inducing and maintaining remission in both Crohn's disease (CD) and ulcerative colitis (UC) [1-5]. However, besides efficacy data, safety assessment is also very important when extrapolating indications for biosimilars. Immunological reactions including immunogenicity and infusion-related reactions are one of the main limiting factors of the originator infliximab (IFX), a chimeric mouse-human monoclonal antibody to TNF-alpha, and one of the most important concerns before the start of using biosimilar IFX. Immediate infusion reactions, developing during the course of the infusion or within 1-2 $\mathrm{h}$ of its completion, are reported in $5-23 \%$ of IBD patients receiving originator IFX [6]. Patients who develop antibodies to IFX have been shown to have a 2 -fold risk of acute infusion reactions and a 6 -fold risk of serious acute infusion reactions [7]. In the two pivotal trials, Programme evaLuating the Autoimmune disease iNvEstigational drug cT-p13 in rheumatoid arthritis (RA) patients (PLANETRA) and Programme evaLuating the Autoimmune disease iNvEstigational drug cT-p13 in ankylosing spondylitis (AS) patients (PLANETAS), comparing CT-P13 with the reference IFX in patients with 
rheumatoid arthritis and ankylosing spondylitis, rates of infusion reactions were $6.6 \%$ and $8.3 \%$ of rheumatoid arthritis patients and $3.9 \%$ and $4.9 \%$ of patients with ankylosing spondylitis for the IFX biosimilar, CT-P13 and for the originator IFX $[8,9]$. Despite these conclusive safety data, immunogenicity of monoclonal antibodies is a major safety concern for the biosimilars. The study published by Ben-Horin et al. in 2015 examined the presence of cross-immunogenicity of IFX biosimilar CT-P13 with the originator drug. Their findings indicated that antibodies to originator IFX developed during the previous exposure to the drug were also cross-reactive with the biosimilar IFX [10]. These data suggest a similar immunogenicity and shared immunodominant epitopes on these two IFX agents.

According to the current central regulation, in Hungary, IFX biosimilar has to be used in every new patient and is allowed to be introduced in patients who previously responded to the reference drug and at least one year elapsed after stopping the originator IFX. Therefore, data on frequency and predictors of infusion reactions developed during the administration of CT-P13 from the clinical practice would be very important when assessing the start of IFX biosimilar. This study aimed to assess the frequency, characteristics and predictors of infusion reactions during CT-P13 therapy.

\section{Patients and methods}

\subsection{Patient population}

This was a prospective, observational, multicenter study carried out in 13 Hungarian and 1 Czech IBD tertiary centers between June 2014 and September 2015. Consecutive IBD patients treated with CT-P13 IFX biosimilar were prospectively enrolled in the study (Inflectra ${ }^{\circledR}$, Hospira was used in Hungary, Remsima ${ }^{\circledR}$, Celltrion was used in the Czech Republic). Eligible patients were older than 18 years and were diagnosed with $C D$ or UC defined by the European Crohn's and Colitis Organisation (ECCO) Consensus Report [11,12]. None of the enrolled patients received originator IFX within 12 months before initiation of CT-P13. Clinical data were collected according to a predefined monitoring strategy. CT-P13 $5 \mathrm{mg} / \mathrm{kg}$ was given as an intravenous infusion at 0,2 , and 6 weeks followed by a maintenance regimen of $5 \mathrm{mg} / \mathrm{kg}$ every 8 weeks except for one Czech patient receiving $10 \mathrm{mg} / \mathrm{kg}$ induction dose for acute, severe disease. Demographic data including history of previous anti-TNF-alpha administration and concomitant medications were collected. Clinical data were recorded, disease activity was evaluated by activity scores and blood samples were collected for the measurement of serum inflammatory parameters (namely, C-reactive protein, leukocyte, hematocrit, thrombocyte, albumin), CT-P13 and anti-drug antibody (ADA) levels during the visits. Clinical response was estimated at fixed appointments throughout the treatment period: at week 2, 4, 6, 14 and then at every 8 weeks.

CT-P13 trough levels and presence of ADA were assessed by ELISA (LISA TRACKER, Theradiag, France in Hungary and SHIKARI Q-Inflixi, Q-ATI, Matriks Biotek, Turkey in the Czech Republic) at baseline, at weeks 14, 30, and 54 right before antiTNF administration.

The detection cut-off value of CT-P13 trough level was 0.1 $\mu \mathrm{g} / \mathrm{ml}$, while $3-7 \mu \mathrm{g} / \mathrm{ml}$ was defined as therapeutic. The standard cut-off value of ADA level was $10 \mathrm{ng} / \mathrm{ml}$. ADA positivity was defined above the cut-off value of ADA level. ADA formation was defined as positive when a patient tested positive for antibody during follow-up on more than two consecutive time points. Association between infusion reactions, demographic and clinical characteristics of patients such as age, gender, smoking habits, type of IBD, extent of disease, perianal involvement, disease activity, previous anti-TNF-alpha, previous and concomitant azathioprine/5-aminosalicylates (5ASA)/corticosteroid use, and ADA positivity were statistically analyzed. Therapy (reduction of the infusion rate, or administration of iv. antihistamine and/or iv. steroid) and outcomes of infusion reactions were prospectively evaluated.

\subsection{Statistics}

Data were analyzed with the use of SPSS 20.0 software. Descriptive statistics were used to characterize patients' demographics and infusion reactions. ADA positivity rates were compared between IFX-exposed and naive patients by $\mathrm{Chi}^{2}$ test or Fisher's Exact test. $p<0.05$ was considered statistically significant.

\section{Results}

\subsection{Patient population}

Three hundred and eighty-four consecutive IBD patients (253 CD patients and 131 UC patients; 291 Hungarian, 93 (zech) were included in the present cohort. Forty-five $C D$ patients and 15 UC patients had received previous anti-TNF-alpha therapy in the Hungarian cohort, and none of the patients in the Czech IBD population. $2.7 \%$ of CD and $4.6 \%$ of UC patients received originator IFX and adalimumab treatment and $21.8 \%$ of CD and $9.4 \%$ of UC patients received only originator IFX prior CT-P13 therapy. Concomitant azathioprine therapy was administered in $146 \mathrm{CD}$ and 62 UC patients at inclusion (Table 1). Mean CT-P13 trough levels were 20.1, 14.7, and $5 \mu \mathrm{g} / \mathrm{ml}$ at weeks 2,6 , and $14(n=124,86$ and 174). ADA measurements were available in 229, 192, and 143 IBD patients at baseline and at 14, 30 weeks. Cumulative ADA positivity rates were $8.7 \%, 19.3 \%$, and $28.0 \%$ in patients at weeks 0,14 , and 30 (Figure 1).

\subsection{Infusion reactions}

Twenty-eight patients $(9.6 \%, 18 \mathrm{CD}, 10 \mathrm{UC})$ developed infusion reaction during the induction and maintenance treatment. Infusion reactions occurred most frequently during the 2 nd and 3rd infusion. The most common symptoms of infusion reactions were flushing in $39.3 \%$, dyspnea and chest pain in $25 \%$ and $14.3 \%$, coughing in $17.8 \%$, palpitation and tachycardia in $10.7 \%$, swelling of the throat in $10.7 \%$ and headache in $7.1 \%$. All of the infusion reactions were mild to moderate. They could be controlled by the reduction of the rate of infusion, or administration of iv. antihistamine or iv. steroid. None of the patients with infusion reaction required to be admitted to intensive care unit. Clinical data of patients who developed infusion reaction are summarized in Table 2. Notably, no significant difference was observed in disease location and 
Table 1. Demographic and clinical data of the Hungarian and Czech IBD patients enrolled in the study.

\begin{tabular}{|c|c|c|c|c|c|c|}
\hline & \multicolumn{2}{|c|}{ Hungarian cohort } & \multicolumn{2}{|c|}{ Czech cohort } & \multicolumn{2}{|c|}{ Total } \\
\hline & $C D$ & UC & $C D$ & UC & $C D$ & UC \\
\hline Patient number & 184 & 107 & 69 & 24 & 253 & 131 \\
\hline Mean age at diagnosis (years) & 23 & 28 & 28.3 & 29.8 & 25.5 & 28.9 \\
\hline Previous anti-TNF-alpha therapy (No.) & 45 & 15 & 0 & 0 & 45 & 15 \\
\hline Concomitant azathioprine therapy (No.) & 111 & 55 & 35 & 7 & 146 & 62 \\
\hline Ileal location (No.) & 31 & 0 & 14 & 0 & 45 & 0 \\
\hline Colonic location (No.) & 60 & 0 & 16 & 0 & 76 & 0 \\
\hline Ileocolonic location (No.) & 90 & 0 & 28 & 0 & 118 & 0 \\
\hline Upper GI location (No.) & 3 & 0 & 11 & 0 & 14 & 0 \\
\hline Stricturing/penetrating behavior (No.) & 76 & 0 & 36 & 0 & 112 & 0 \\
\hline Perianal disease (No.) & 64 & 0 & 21 & 0 & 85 & 0 \\
\hline Previous surgery (No.) & 41 & 0 & 21 & 0 & 62 & 0 \\
\hline Proctitis (No.) & 0 & 9 & 0 & 1 & 0 & 10 \\
\hline Left-sided UC (No.) & 0 & 35 & 0 & 9 & 0 & 44 \\
\hline Extensive colitis (No.) & 0 & 63 & 0 & 14 & 0 & 77 \\
\hline Patients with ADA positivity & 21 & 19 & 3 & 0 & 24 & 19 \\
\hline
\end{tabular}

Cumulative ADA pozitivity rates in enrolled patients at week 0,14 and 30

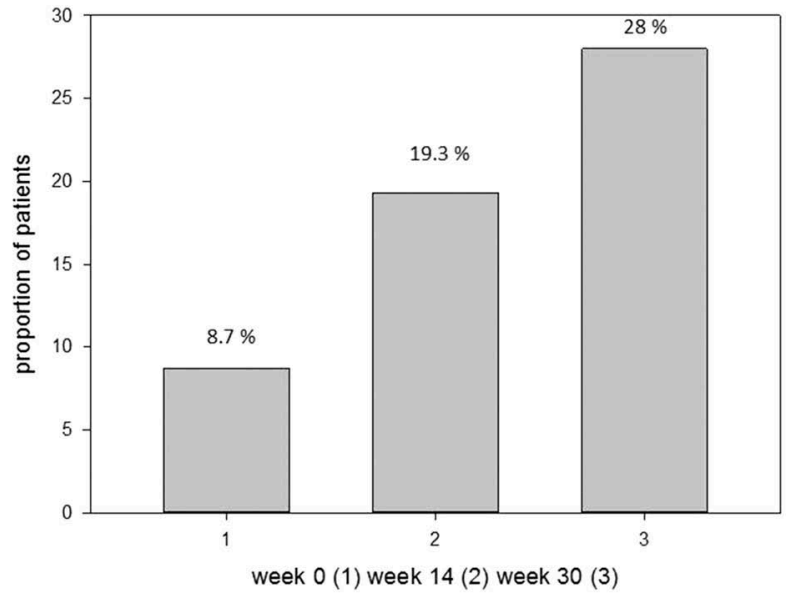

Figure 1. Cumulative ADA positivity rates in enrolled patients $(8.7 \%, 19.3 \%$ and $28 \% ; n=229,192$ and 143 ) at weeks 0,14 , and 30 .

behavior between patient groups with and without developing infusion reactions.

In $C D$ patients with infusion reaction, prior to biological therapy with CT-P13 therapy, 15 patients received 5-ASA, 14 corticosteroid and 9 patients immunomodulator therapy ever during the disease course. Thirteen $C D$ patients with infusion reaction received previous anti-TNF-alpha treatment; every patient was treated with originator IFX. Regarding UC patients who developed infusion reaction, prior to CT-P13 therapy 8 patients was treated with 5-ASA, 7 with corticosteroid and 5 with immunomodulator therapy during their whole disease course. Five UC patients with infusion reaction were previously treated anti-TNF-alpha drug; three of them with originator IFX, and 2 patients with adalimumab. Overall, infusion reactions occurred in 10 of 231 anti-TNF-alpha naive patients (4.3\%). ADA positivity was detected in $10 \mathrm{CD}$ and $4 \mathrm{UC}$ patients (8 $\mathrm{CD}$ and 3 UC patients were previously treated with anti-TNFalpha therapy) of 28 patients who developed infusion reaction (Figure 2). Concomitant corticosteroid and azathioprine were given for 7 and 9 CD and for 3 and 5 UC patients developing infusion reaction during the CT-P13 therapy, respectively. Dose escalation of CT-P13 from $5 \mathrm{mg} / \mathrm{bwkg}$ to $10 \mathrm{mg} / \mathrm{bwkg}$ was necessary in two patients (one $C D$, one $U C$ ) with infusion reaction during maintenance therapy.

CT-P13 therapy had to be stopped in 17 patients and was switched to adalimumab in 12 patients. However, in 11 (39.3\%) patients, CT-P13 therapy was continued with the use of premedication (reduction of the rate of infusion, or administration of iv. antihistamine or iv. steroid). Four patients who continued CT-P13 therapy with the use of premedication presented ADA positivity.

Infusion reactions did not occur in the Czech population; moreover rate of infusion reaction was significantly higher in anti-TNF-a naïve Hungarian patient than in anti-TNF-a naïve Czech patients $(p=0.032)$. Previous anti-TNF-alpha exposure (30\% vs. $3.1 \%, p<0.001$, OR $6.3(2.7-14.6)$ ) and ADA positivity (32.6\% vs. $4.1 \%, p<0.001$, OR 19 [5-73]) during the induction therapy were predictive to the development of infusion reactions (Figures 3 and 4). No association was shown between infusion reaction and gender, smoking status, type of disease, extent/location, perianal involvement, disease activity, concomitant or previous 5-ASA/steroids, and azathioprine therapy.

\section{Discussion}

This multicenter, prospective study examined the rate, the characteristics, and the predictors of infusion reactions developed in CT-P13-treated Hungarian and Czech IBD patients. Infusion reactions occurred in $7.3 \%$ of all the enrolled patients. $35.7 \%$ of patients developing infusion reaction were anti-TNF naive. Frequency rate of infusion reactions proved to be $9.6 \%$ of the Hungarian patients in $64.3 \%$ of CD and $35.7 \%$ of UC patients. Anti-CT-P13 antibody was proved in $32.6 \%$ of patients with infusion reaction and $4.1 \%$ of subjects without any reaction during treatment. Infusion reactions occurred most frequently during the 2 nd and 3 rd infusions. The most common symptoms of infusion reactions included flushing, dyspnea, and chest discomfort. CT-P13 therapy had to be stopped in the majority of the patients after the development of an infusion reaction and switch to adalimumab was carried out in $43 \%$ of them. CT-P13 therapy was continued with the use of simple or combined premedication including reduction of the infusion rate or use of antihistamine or steroid in almost $40 \%$ of the patients.

Infusion reactions are one of the most common limiting factors of IFX therapy. Several possible mechanisms may be in 
Table 2. Characteristics of patients developing infusion reaction.

\begin{tabular}{lrc}
\hline & $\begin{array}{c}\text { CD with infusion } \\
\text { reaction }(n=18)\end{array}$ & $\begin{array}{c}\text { UC with infusion } \\
\text { reaction }(n=10)\end{array}$ \\
\hline Gender (male/female) & $6 / 12$ & $5 / 5$ \\
Mean age at diagnosis (years) & 22 & 27 \\
Mean disease duration (years) & 7 & 5 \\
Previous therapy & 15 & 8 \\
1. 5-ASA & 14 & 7 \\
2. Corticosteroid & 9 & 5 \\
3. Azathioprine & 13 & 5 \\
4. Anti-TNF-alpha & & \\
Concomitant therapy at the & & \\
$\quad$ time of infusion reaction & 7 & 3 \\
1. Corticosteroid & 9 & 5 \\
2. Azathioprine & 10 & 4 \\
3. ADA positivity & 655 & 743 \\
Mean value of ADA titer at & & \\
$\quad$ infusion reaction (ng/ml) & & \\
Number of infusions at infusion & & \\
$\quad$ reaction & 11 & 3 \\
4. 2nd infusion & 4 & 1 \\
5. 3rd infusion & 2 & \\
6. 4th infusion & 1 & \\
7. 5th infusion & & \\
\hline
\end{tabular}

Serum ADA level in patients with infusion reaction

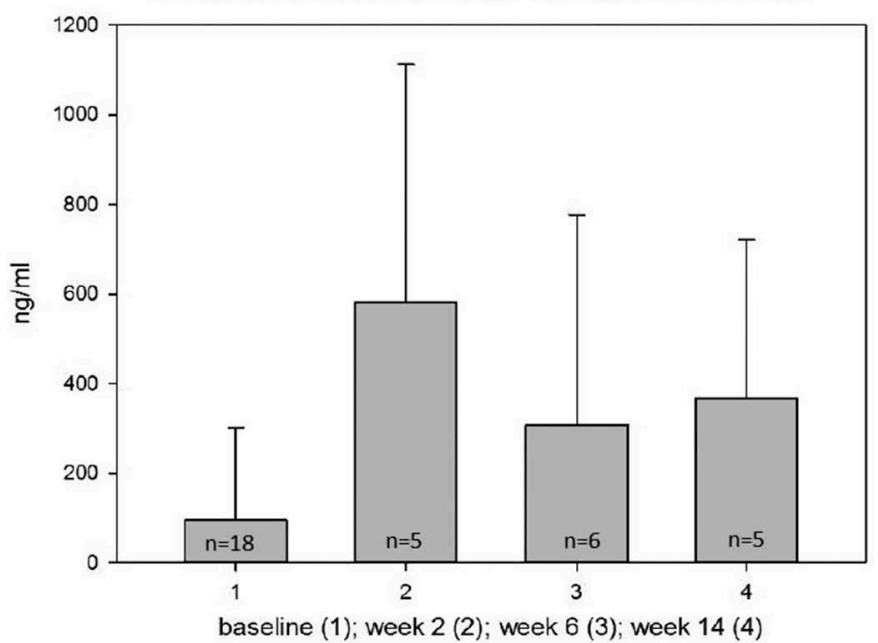

Figure 2. Serum ADA level distribution in patients with infusion reaction at weeks $0,2,6$ and 14 . the background of infusion reactions including cytokine release (immune cell hyperactivation, direct apoptosis, complement-mediated lysis, antibody-dependent cellular toxicity), IgE-mediated hypersensitivity reactions to IFX, IgG anaphlyaxis, complement activation, or direct mast cell degranulation [13-15]. The most frequent symptoms of infusion reaction are pruritus, flushing, dyspnea, chest discomfort, hypertension, myalgia, nausea, urticaria, headache, rash, and dizziness [16]. Although there is no specific guideline for the treatment of IFX-related infusion reactions, according to therapeutic recommendations based on case reports and expert opinions, temporary attenuation of the infusion rate or temporary interruption of the infusion with the administration of medications for symptom control are usually eligible. Coadministration of immunomodulator or premedication with steroids and/or antihistamines is the most common interventions in the prevention of infusion reactions [6]. However, only a smaller proportion of patients may continue treatment with these premedications - in our study, almost $40 \%$ of the patients could maintain CT-P13 treatment with supplementary intervention and premedication.

Frequency rate of infusion reactions in CD patients seems to be different when comparing to the large randomized clinical trials conducted in $\mathrm{CD}$ patients receiving the originator IFX. The incidence of infusion reactions was $16 \%$ and $21 \%$ in ACCENT I and II studies, respectively $[17,18]$. The lowest incidence of infusion reactions occurred among patients receiving both steroids and immunosuppressives (8\%) [17]. In our cohort, $9.8 \%$ of the $C D$ patients developed infusion reaction, which is lower than that of the ACCENT trials. In ACT 1 and 2 infusion reactions occurred in $9.9 \%$ and $11.6 \%$ of UC patients receiving $5 \mathrm{mg}$ of IFX [19]. These results are highly similar to our data where infusion reactions occurred in $9.3 \%$ of the UC patients. In ACT 1, 35.7\% of patients with antibody positivity against IFX developed infusion reaction at week 54 [19].

Although the increasing data about the efficacy of IFX biosimilar confirmed that CT-P13 may be considered equivalent to its reference drug in IBD in practice, collection of immunogenicity data and immunological reactions in clinical practice is important to compare the safety profile of the biosimilar and the reference product especially if we only consider the 'Eprex

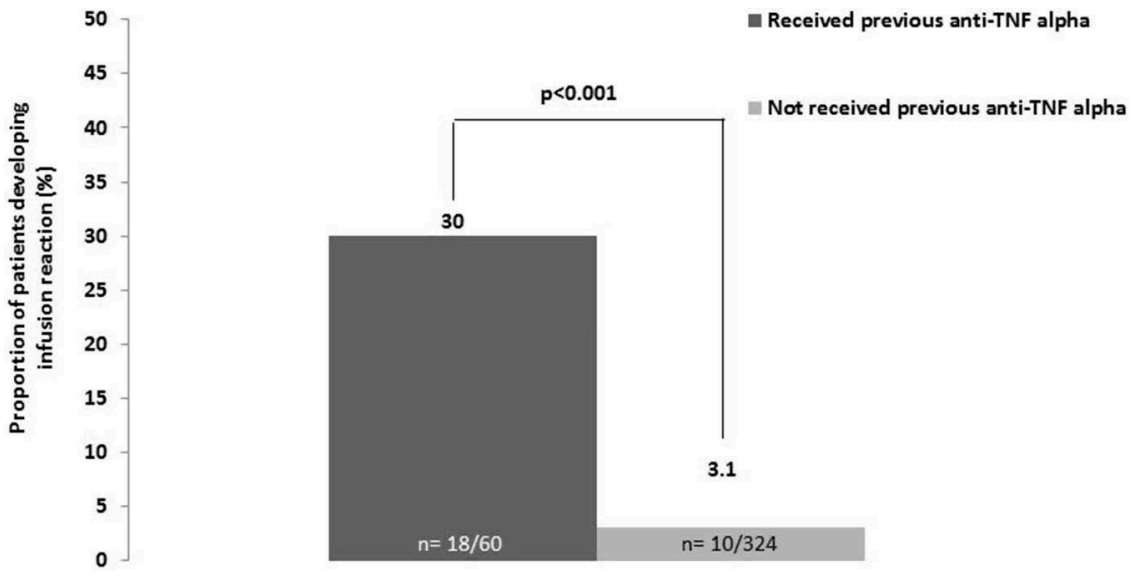

Figure 3. Proportion of patients developing infusion reaction regarding previous anti-TNF-alpha use. 


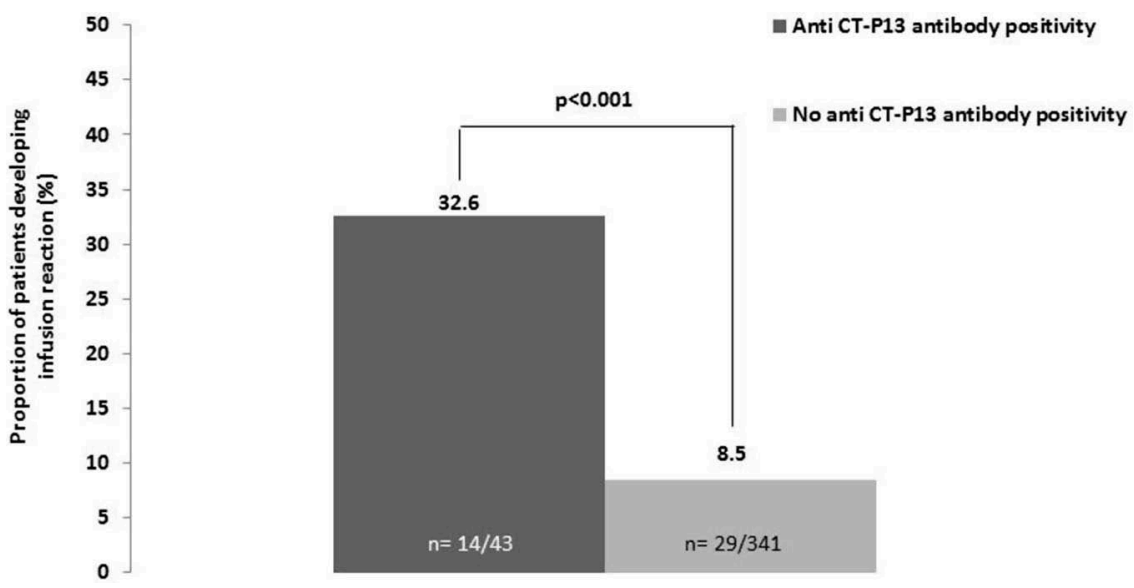

Figure 4. Proportion of patients developing infusion reaction regarding anti CT-P13, an IFX biosimilar antibody.

case,' when after a change in the formulation of epoetin-alfa, patients developed antibodies against both the administered epoetin and the endogenous erythropoietin, resulting in severe pure red cell aplasia [20]. However, no relevant differences were noted in the immunogenicity profiles of CT-P13 and reference IFX in the PLANETRA and PLATENAS studies from rheumatology $[8,9]$. In the Korean study by Kang et al., no serious adverse reaction occurred during CT-P13 therapy [3]. Yung et al. experienced adverse events in 6 UC patients (11.8\%) including allergic (skin rash, scaling of palm) and infusion reaction in half of these patients [2].

In the Norwegian prospective study, one CD and one UC patients developed infusion reaction [1]. The UC patient with infusion reaction occurring at the second infusion was shown to have undetectable trough serum levels of CT-P13 and ADA positivity at week six. This patient had previously been treated with IFX in two periods [1]. None of these studies were powered enough to obtain predictive factors for infusion reactions. Infusion reaction did not occur in the Czech population, using Remsima. In September 2013, the EMA issued the marketing authorization of a biosimilar of Remicade, CT-P13, to 2 applicants, Celltrion Inc. (Incheon, South Korea) and Hospira Inc. (Lake Forest, IL) under the trade names Remsima and Inflectra $[21,22]$. However, Remsima and Inflectra can be considered as one product since they are both manufactured by Celltrion. Although considered to have no clinical impact, differences in impurities and break down products of the biosimilars can affect immunogenicity. According to the recent study by Gils et al., monoclonal antibodies raised against the originator product Remicade revealed a highly similar reactivity toward the biosimilars Remsima and Inflectra and with similar $K_{D}$ values for both antibodies toward the different infliximab molecules [23]. In the present study, LISA TRACKER (Theradiag, France) and Matriks Biotek (Turkey) were used to measure IFX biosimilar trough level and ADA concentration. However, according to a recent Czech study, SHIKARI Q-Inflixi (Matriks Biotek, Turkey), LISATracker Duo Infliximab (Theradiag, France), and RIDASCREEN IFX (R-Biopharm, Germany) assays were in perfect agreement in qualitative and quantitative results for the majority of the samples.
These observations suggested that substitution between the assay methods evaluated in the study is possible [24].

Our results showed that previous anti-TNF- $a$ exposure and presence of antidrug antibody proved to predict the development of infusion reaction. Contrary to the Hungarian cohort, Czech population involved only anti-TNF-alpha naïve IBD patients. Considering these data, the absence of previous anti-TNF-alpha exposure and ADA positivity may be the reason for the lack of infusion reaction in the Czech cohort. However, this study has no power to assess differences regarding to immunogenicity between Inflectra and Remsima.

In conclusion, this large, multicenter study was the first that evaluated the immunogenicity profile of CT-P13 in IBD in the clinical practice, characterized infusion reactions in this population and revealed predictors for infusion reaction. Our results suppose a lower immunogenicity of the biosimilar in CD and similar rates and characteristics of infusion reaction with the originator. These data should be confirmed by other large studies with the consideration of potential differences in the characteristics of the patient population and the disease phenotype.

\section{Funding}

This paper was supported by the János Bolyai Research Scholarship of the Hungarian Academy of Sciences (BO/00632/14/5), by the ÚNKP-ÚNKP-16-4 New National Excellence Program of the Ministry of Human Capacities and by the research grant of the National Research, Development and Innovation Office (Grant ID: 119809).

\section{Declaration of interest}

The authors have no other relevant affiliations or financial involvement with any organization or entity with a financial interest in or financial conflict with the subject matter or materials discussed in the manuscript apart from those disclosed.

\section{ORCID}

Anna Fábián (D) http://orcid.org/0000-0002-0824-7476 


\section{References}

Papers of special note have been highlighted as either of interest $(\cdot)$ or of considerable interest $(\cdot \bullet)$ to readers.

1. Jahnsen J, Detlie TE, Vatn S, et al. Biosimilar infliximab (CT-P13) in the treatment of inflammatory bowel disease: a Norwegian observational study. Expert Rev Gastroenterol Hepatol. 2015;9:45-52.

2. Jung YS, Park DI, Kim YH, et al. Efficacy and safety of CT-P13, a biosimilar of infliximab, in patients with inflammatory bowel disease: a retrospective multicenter study. J Gastroenterol Hepatol. 2015;30:1705-1712.

3. Kang YS, Moon HH, Lee SE, et al. Clinical experience of the use of CT-P13, a Biosimilar to infliximab in patients with inflammatory bowel disease: a case series. Dig Dis Sci. 2015;60:951-956.

4. Farkas $K$, Rutka $M$, Bálint $A$, et al. Efficacy of the new infliximab biosimilar CT-P13 induction therapy in Crohn's disease and ulcerative colitis - experiences from a single center. Expert Opin Biol Ther. 2015;15:1257-1262.

5. Gecse KB, Lovász BD, Farkas $K$, et al. Efficacy and safety of the biosimilar infliximab CT-P13 treatment in inflammatory bowel diseases: a prospective, multicentre, nationwide cohort. J Crohns Colitis. 2016;10:133-140.

- This was the first prospective, multicenter study confirming the efficacy and safety of biosimilar infliximab CT-P13 treatment in inflammatory bowel diseases.

6. Lichtenstein L, Ron Y, Kivity $S$, et al. Infliximab-related infusion reactions: systematic review. J Crohns Colitis. 2015;9:806-815.

7. O'Meara S, Nanda KS, Moss AC. Antibodies to infliximab and risk of infusion reactions in patients with inflammatory bowel disease: a systematic review and meta-analysis. Inflamm Bowel Dis. 2014;20:1-6.

8. Yoo DH, Hrycaj $P$, Miranda $P$, et al. A randomised, double-blind, parallel-group study to demonstrate equivalence in efficacy and safety of CT-P13 compared with innovator infliximab when coadministered with methotrexate in patients with active rheumatoid arthritis: the PLANETRA study. Ann Rheum Dis. 2013;72:1613-1620.

. This was a phase III randomized, double-blind, multicenter, multinational, parallel-group study demonstrating equivalent efficacy to innovator infliximab at week 30, with a comparable pharmacokinetics, safety and immunogenicity profile in patients with active rheumatoid arthritis.

9. Park W, Hrycaj P, Jeka S, et al. A randomised, double-blind, multicentre, parallel-group, prospective study comparing the pharmacokinetics, safety, and efficacy of CT-P13 and innovator infliximab in patients with ankylosing spondylitis: the PLANETAS study. Ann Rheum Dis. 2013;72:1605-1612.

- This was a phase I randomized, double-blind, multicenter, multinational, parallel-group study demonstrating equivalent efficacy, safety and pharmacokinetic profiles of CT-P13 and innovator infliximab at week 30 in patients with active ankylosing spondylitis.

10. Ben-Horin S, Yavzori M, Benhar I, et al. Cross-immunogenicity: antibodies to infliximab in Remicade-treated patients with IBD similarly recognise the biosimilar Remsima. Gut. 2015;0:1-7.

11. Van Assche G, Dignass A, Panes J, et al. The second European evidence-based Consensus on the diagnosis and management of
Crohn's disease: definitions and diagnosis. J Crohns Colitis. 2010;4:7-27.

12. Dignass A, Eliakim R, Magro F, et al. Second European evidence-based consensus on the diagnosis and management of ulcerative colitis part 1: definitions and diagnosis. J Crohns Colitis. 2012;6:965-990.

13. Vultaggio A, Maggi E, Matucci A. Immediate adverse reactions to biologicals: from pathogenic mechanisms to prophylactic management. Curr Opin Allergy Clin Immunol. 2011;11:262-268.

14. Vultaggio A, Matucci A, Nencini $F$, et al. Anti-infliximab IgE and non-IgE antibodies and induction of infusion-related severe anaphylactic reactions. Allergy. 2010;65:657-661.

15. Jiao D, Liu Y, Lu X, et al. Characteristics of anaphylaxis-inducing IgG immune complexes triggering murine passive systemic anaphylaxis. Allergy. 2013;68:236-245.

16. Choquette $D$, Faraawi $R$, Chow $A$, et al. Incidence and management of infusion reactions to infliximab in a prospective real-world community registry. J Rheumatol. 2015;42:1105-1111.

17. Hanauer SB, Feagan BG, Lichtenstein GR, et al. Maintenance infliximab for Crohn's disease: the ACCENT I randomized trial. Lancet. 2002;359:1541-1549.

18. Sands $\mathrm{BE}$, Anderson $\mathrm{FH}$, Bernstein $\mathrm{CN}$, et al. Infliximab maintenance therapy for fistulizing Crohn's disease. N Engl J Med. 2004;350:876-885.

.- This multicenter, double-blind, randomized, placebo-controlled trial revealed at the first time that patients with fistulizing Crohn's disease who have a response to induction therapy with infliximab have an increased likelihood of a sustained response over a 54-week period if infliximab treatment is continued every 8 weeks.

19. Rutgeerts $P$, Sandborn WJ, Feagan BG, et al. Infliximab for induction and maintenance therapy for ulcerative colitis. N Engl J Med. 2005;353:2462-2476.

.- The Active Ulcerative Colitis Trials 1 and 2 (ACT 1 and ACT 2) confirmed the efficacy of infliximab for induction and maintenance therapy in adults with ulcerative colitis.

20. Schellekens $\mathrm{H}$. Immunological mechanism of EPO-associated pure red cell aplasia. Best Pract Res Clin Haematol. 2005;18:473-480.

21. European Medicines Agency: Remsima. European Public Assessment Report. [cited 2015 Jul 23]. Available from: http:// www.ema.europa.eu/docs/en_GB/document_library/EPAR_Public_assessment_report/human/002576/WC500151486.pdf

22. European Medicines Agency: Inflectra. European Public Assessment Report. cited 2015 Jul 23]. Available from: http://www.ema.europa. eu/docs/en_GB/document_library/EPAR_Summary_for_the_pub lic/human/002778/WC500151491. pdf

23. Gils A, Van Stappen T, Dreesen E, et al. Harmonization of infliximab and anti-infliximab assays facilitates the comparison between originators and biosimilars in clinical samples. Inflamm Bowel Dis. 2016;22:969-975.

24. Malicková K, Duricová D, Bortlik M, et al. Serum trough infliximab levels: a comparison of three different immunoassays for the monitoring of CT-P13 (infliximab) treatment in patients with inflammatory bowel disease. Biologicals. 2016;44: 33-36.

- This study demonstrated a good correlation of CT-P13 serum level detection between Matriks Biotek, Theradiag, and R-Biopharm assays. 